\title{
FACTORIAL STRUCTURE AND PSYCHOMETRIC PROPERTIES OF ATTITUDES TO ECONOMIC DEPENDENCE OR INDEPENDENCE IN A SAMPLE OF BULGARIAN CITIZENS
}

\author{
Bilyana B. Yordanova, Lyudmil D. Krastev, Nikolay Iv. Ivantchev \\ E-mail: b_iordanova@swu.bg, iris@swu.bg, nikyart@yahoo.com \\ South-West University, Blagoevgrad, Bulgaria
}

\begin{abstract}
Rising interactions of asymmetrical exchange as a consequence of unequal access to economic resources create status differences between people. In that way some people are provided with authority benefits while the others are in dependent position. The situation of economic dependence arises when the object is seen by the subject like a unique source for personal needs gratification. The degree of dependence is right proportional to the object's subjective significance for a particular person, group, organization, etc. This statement provokes the problem of dependence as a psychological phenomenon that defines personal behavior and the character of interactions in respect of actual needs gratification. Contrary, economic independence is associated with these resources that are the result of personal incomes, property, and capital dividends.
\end{abstract}

Key words: attitudes, dependence, independence, psychometric properties, structure.

\section{Introduction}

It is possible to define some basic components that are related to different aspects of economic dependence. In the first place, the dependent subject feels in high degree the need of a specific object, material goods or economic resources. The provider is a subject that owns these goods or resources and controls the access to them. In this sense, the provider owns the monopoly required for dependent objects and the provider appears as no alternative supplier. At the same time the dependent person is not a unique supplier of resources that are necessary for the provider. This means that the dependent person is expendable for the provider. That is why the supplier is much more interested in the provider than vice versa. Because of this, the provider receives the benefits of power controlling the conditions for providing these resources that are necessary for the dependant person. Such interaction secured unfavorable position for the dependent person by limiting his access to the resources and forming dependent behavioral strategies (Hirschman, 1970).

The opportunity or the ability to be offered unique rare resources stops the occurrence of relations associated with the economic dependence. Good professionals have specific skills and abilities to provide themselves a high degree of independence even when there is a disadvantage in the labor market (Ferrer-i-Carbonell, 2005). In interpersonal interactions high subjective importance of the participants for each other prevents the emergence of powerful relations - and therefore dependent economically family members can be equal participants in the distribution of intra-family budget. 
Attitudes and values are referred to the characteristics, realizing subjective manifestations of economic dependence that replace the responsibility for individual financial well-being. In this case, the dependence of the subject appears in his mind as normative values associated with the transfer of responsibility to someone else (the belief that the state is responsible for the welfare of its citizens) (Yordanova, 2012). In practice, very often on the ground of social and economic dependence as a mental phenomenon are leading cognitive, emotional and behavioral components of the dependent person's attitudes. According to this view, life satisfaction varies around a set point, which is a personal baseline that remains constant over time. A number of studies have suggested that life satisfaction set point can be adjusted by negative life events such as unemployment and changes in marital status for example (Lucas et al., 2004). Extreme socio-economic situations can stimulate some people to economically active actions, while the others react with passivity and manifestations of "learned helplessness." In this sense, the responsibility for economic dependence has personal dispositions, external locus of control, low self-esteem, lack of confidence in one's own skills, fear of change, risk actions and the subjective perceptions of the specific individual.

Power can be seen as the ability of a subject to require other subjects to act in his favor that they would not make voluntarily. The provider has the power that is directly proportional to the subjects' economic dependence and there is so much power that many valuable resources are controlled by the provider. The power increases in these cases where the dependent person has no alternative interactions to obtain the required resources and is in high degree exchangeable for the provider. Power advantage can be the ultimate goal for the aspirations of the provider or to control his access to other resources valuable to him (social, cultural, political). Power structures enable the provider to unlimited access of material goods, social control and political impact on the entire social system (Poggi, 2001).

To the characteristics of a dependent person refer not only belief in their own helplessness and attitudes for social assistance but also unconditional loyalty to the provider and the fear of losing his support. To keep the dependent person in this state, purposefully a complex of moral obligations to the provider is formed in him. For this reason, in these relations unlike the equivalent relations (market trade), the dependence is usually presented by moral and emotional component through which the provider assumes the role of a benefactor who cares for the dependent person (Barry, 1976).

There are some possibilities (though difficult to implement in practice) to disrupt these relations and their transformation into equal, symmetrical exchange. This process can only be done by the dependent person because the provider is interested in the safeguarding and strengthening of dependent relations. For example, individual economic dependence from the state or the employer can be overcome only with the will of a dependent person himself by mobilization of his intellectual, creative and emotional and personal resources. The studies reveal that in the relationships where one of the partners has large economic power, there is a high degree of mistrust and suspicion (Molm, Takahashi \& Peterson, 2000).

Economic vulnerability of the dependent person is related primarily to the risk of the dependency relationship. Therefore, a dependent person depends chiefly on external support for obtaining the necessary goods and forms passive strategies in self economic behavior. The dependent rejects self responsibility for individual actions and doesn't make any attempts to achieve personal economic goals in exchange for the hope that all this will be done by the provider. Economic inactivity prevents the development of these personal qualities that the subject will be able to offer in the process of economic exchange with others and to derive more benefit from it than from a personal relationship with the provider (Sweeney \& McFarlin, 2004). Therefore, in case of suspended relationship of dependency, such person appears to be helpless and socially incompetent, i.e. does not possess the social skills and psychological qualities for successful economic adaptation. The dependent's conviction that only others are responsible for his well-being puts him in passive expectance and constant dependency from the provider.

Attitudes towards economic independence characterize the "independent" strategies of economic behavior and form independence as a vital position. Independent strategies of economic behavior suggest perceiving difficult economic situations as a challenge, where despite the existing risk, new potential opportunities are discovered. Realization of economic independence as a 
Bilyana B. YORDANOVA, Lyudmil D. KRASTEV, Nikolay Iv. IVANTCHEV. Factorial Structure and Psychometric Properties of Attitudes to Economic Dependence or Independence in a Sample of Bulgarian Citizens

behavioral strategy is associated with the mobilization of individual skills and abilities to cope with a complex economic situation and aims to increase the financial well-being and social status of the individual.

Attitudes towards economic dependence are directed to justify personal passivity and inability of the individual who tries to provide himself a relatively acceptable level of wealth. These attitudes form "dependent" strategies of economic behavior that are aimed at using external sources to solve the economic problems as awaiting assistance from the state or high resource subjects, and transferring upon them rights and freedoms in exchange for care or receiving social welfare.

\section{Methodology of research}

\section{Participants}

The presented theoretical positions provoke a desire to divide all respondents into groups according to their established attitudes of economic dependence or independence. Such classification tempts to distinguish the groups and participants to be separated as economically ,successful " or „unsuccessful“; „,oriented towards market“ or „disoriented“ according to their perceptions of economic dependence or independence. No doubt in market reality such classifications will have only a theoretical value because the actual economic behavior cannot be predicted on the basis of economic attitudes of individuals. Therefore, this study concerns the content and characteristics of attitudes towards economic dependence or independence in market economy.

Table 1. Demographic characteristics of the respondent sample

\begin{tabular}{clcc}
\hline \multirow{2}{*}{ Demographic characteristics } & N & $\%$ \\
\hline \multirow{2}{*}{ Gender } & Males & 381 & 48.6 \\
& Females & 403 & 51.4 \\
\hline \multirow{2}{*}{ Family status } & Single & 258 & 32.9 \\
& Married & 377 & 48.1 \\
& Divorced & 149 & 19 \\
\hline \multirow{3}{*}{ Age } & $18-35$ & 186 & 23.7 \\
& $36-50$ & 232 & 29.6 \\
& $51-65$ & 224 & 28.6 \\
& Over 61 & 136 & 17.3 \\
\hline \multirow{3}{*}{ Educational degree } & Completed 8th Grade & 208 & 26.6 \\
& Completed High-School & 317 & 40.4 \\
& Completed University & 259 & 33 \\
\hline \multirow{3}{*}{ Occupation } & Students & 163 & 20.8 \\
& Jobholders & 214 & 27.3 \\
& Pensioners & 126 & 16.1 \\
& Unemployed & 138 & 17.6 \\
& Businessmen & 143 & 18.2 \\
\hline \multirow{2}{*}{ Incomes } & To 320 BGL & 218 & 27.8 \\
& $321-600$ BGL & 307 & 39.2 \\
& $601-900$ BGL & 126 & 16.1 \\
& $901-1200$ BGL & 85 & 10.8 \\
& Over 1200 BGL & 48 & 6.1 \\
\hline
\end{tabular}

The study was conducted between September and December 2013. Participants of the study 
consisted of 784 Bulgarian citizens from Blagoevgrad and Sofia. All the participants participated

in the study voluntarily. The data collection and its analysis were done anonymously.

\section{Procedure}

A special questionnaire was used that consisted of 21 items expressing attitudes of individual economic dependence or independence. It was not necessary to calculate the total score for the entire test, but it only tends to assign the respondents to the category of economically dependent or independent personalities. The attitudes from concrete factor are strongly manifested at a higher positive score, while at lower - unfavorable (Krastev, L. 2007)

The participants were asked to complete the questionnaire. They were told that their responses would be treated confidentially and anonymously. The entire procedure took 45 minutes. Participants were invited to indicate their interest in completing the same questionnaire again in November 2013. Those who indicated the interest to do so, were approached again for filling in the questionnaire for the second time. Analysis was computed using the data collected during the first session. The data gathered from the second session were only used for establishing test-retest reliability scores.

\section{Hypotheses}

The relationships of personality to social and economic reality determine the characteristics and components of attitudes towards economic dependence or independence.

Perhaps certain differential-psychological characteristics exist according to participants' perceptions of economic dependence or independence.

\section{Data Analysis}

The data were collected using a survey form which was distributed randomly. SPSS was used to perform statistical analysis of the data collected from the survey forms. The methodologies used were:

Descriptive statistics was used for establishing frequency and percentages of the respondents.

Factor analysis was conducted to present the structure of economic dependence or independence. Bartlett's test of sphericity and the Kaiser Meyer Olkin measure of sampling adequacy are both tests that can be used to determine the factoriability of the matrix as a whole. The results' value of Bartlett's test of sphericity was significant $(\mathrm{p}<0.001, \mathrm{p}=0.000)$. In addition, the Kaiser Meyer Olkin measure was 0.803 which was greater than 0.6 , so factorability was assumed.

Student's t-test was used for assessing the statistical significance of the difference between two sample means or the construction of confidence intervals for the difference between two population means

F-statistic was used for testing the statistical significance of the model or components in the model.

\section{Results of Research}

Factor analysis by the method of principal components (Varimax rotation), differentiated three-factor structure of items explaining $45.9 \%$ of the total variance $(\mathrm{KMO}=0.803$ and Sig of Bartlett's Test $=0,000$ ) 
Table 2. Item loads for first factor.

\begin{tabular}{|c|c|c|c|}
\hline Items & $\begin{array}{c}\text { First factor } \\
\text { (Economic Dependency) } \\
21,6 \% ; \alpha=0,7901\end{array}$ & $\begin{array}{c}\text { Second factor } \\
\text { (Economic Independency) } \\
19,7 \% ; \alpha=0,7826\end{array}$ & $\begin{array}{c}\text { Third factor } \\
\text { (Neutral) } \\
4,6 \% ; \alpha=0,2405\end{array}$ \\
\hline 17 & 0,794 & 0,025 & 0,080 \\
\hline 11 & 0,788 & 0,022 & 0,069 \\
\hline 5 & $-0,767$ & 0.108 & 0,030 \\
\hline 15 & 0,693 & 0,013 & 0,202 \\
\hline 21 & 0,676 & 0,206 & 0,019 \\
\hline 9 & 0,575 & $-0,018$ & 0,108 \\
\hline 14 & $-0,537$ & 0,065 & 0,206 \\
\hline 7 & 0,474 & 0,053 & $-0,004$ \\
\hline 3 & 0,461 & 0,102 & 0,126 \\
\hline 13 & 0,464 & 0,032 & $-0,059$ \\
\hline
\end{tabular}

The first factor describes $21.6 \%$ of the variation and covers 9 items reflecting the attitudes of the economically dependent person. This factor includes some representations that are typical for low-resource economic objects (passiveness, low claims, uncertainty and insecurity in self abilities and opportunities, demanding for external assistance and support, readiness for savings and financial deprivation, ineffective behavioral strategies aimed at ensuring minimum acceptable level of material well-being, the ideal of a good employer, etc.). There are 36 possible correlations between items in the first factor where only 10 correlations are not significant. All items in this factor have good discriminatory power and correctly distinguish individuals who have lower scores on the scale from those with the high score on it $(\mathrm{p}<0.05)$.

Table 3. Item loads for the second factor.

\begin{tabular}{cccc}
\hline Items & $\begin{array}{c}\text { First Factor } \\
\text { Economic Dependency } \\
\mathbf{2 1 , 6 \% ;} \alpha=\mathbf{0 , 7 9 0 1}\end{array}$ & $\begin{array}{c}\text { Second Factor } \\
\text { Economic Independency } \\
\mathbf{1 9 , 7 \% ;} \alpha=\mathbf{0 , 7 8 2 6}\end{array}$ & $\begin{array}{c}\text { Third Factor } \\
\text { Neutral } \\
\mathbf{4 , 6 \% ;} \alpha=\mathbf{0 , 2 4 0 5}\end{array}$ \\
\hline 16 & $-0,009$ & 0.862 & 0,119 \\
20 & 0,028 & 0,790 & 0,162 \\
8 & 0,121 & 0,786 & 0,063 \\
2 & 0,307 & 0,740 & 0,008 \\
10 & 0,118 & $-0,684$ & $-0,006$ \\
6 & 0,058 & 0,645 & 0,262 \\
4 & 0,078 & 0,637 & 0,108 \\
12 & 0,096 & 0,473 & $-0,042$ \\
\hline
\end{tabular}

The second factor consists 8 items that explain $19.7 \%$ of the total dispersion, and can be called „economic independence“. No doubt this factor reflects attitudes related to economic independence and expresses representations for the high-resource economic subjects (self-confidence and self ability to achieve economic success, high self-esteem and willingness to take big economic risks, activeness, businesslike and entrepreneurship, perseverance to achieve a successful career, readiness for a new job, depending on the economic situation, security and the ability to control economic difficulties).

There were 28 possible correlations between items in the second factor where only 8 were not significant. All items in this factor had good discrimination power and better distinguished these individuals who have a high score from those with lower scores on the scale $(\mathrm{p}<0,05)$. 
Table 4. Item loads for the second factor.

\begin{tabular}{cccc}
\hline Items & $\begin{array}{c}\text { First factor } \\
\text { Economic dependency } \\
\mathbf{2 1 , 6 \% ;}\end{array}$ & $\begin{array}{c}\text { Second factor } \\
\text { Economic independency } \\
19,7 \% ; \alpha=0,7826\end{array}$ & $\begin{array}{c}\text { Third factor } \\
\text { Neutral } \\
\mathbf{4 , 6 \% ;} \alpha=\mathbf{2 4 0 5}\end{array}$ \\
\hline 19 & 0,201 & 0,062 & 0,528 \\
1 & $-0,012$ & 0,089 & 0,470 \\
18 & 0,033 & 0,124 & 0,461 \\
\hline
\end{tabular}

The third factor involves three items, but its reliability is too low and therefore it has not been interpreted.

The analysis of the results concerning the differential psychological characteristics of the respondents according to their attitudes shows some significant differences by gender, marital status, level of education, age and requested financial status (monthly income).

Table 5. Gender differences.

\begin{tabular}{cccccccc}
\hline Score & Gender & $\mathbf{N}$ & $\bar{X}$ & SD & df & t & $\mathbf{p}$ \\
\hline $\begin{array}{c}\text { First } \\
\text { factor }\end{array}$ & Men & 381 & 8,032 & 5,858 & 781 & 5,857 & 0.000 \\
\hline Wecond & Men & 402 & 10,541 & 6,154 & & & \\
factor & 380 & 9,283 & 5,876 & 779 & 0,723 & 0.794 \\
\hline
\end{tabular}

Significant gender differences were observed in the first factor. Women are more likely to manifest attitudes relating to economic dependence.

Table 6. Differences by family status.

\begin{tabular}{|c|c|c|c|c|c|c|c|}
\hline Score & Family status & $N$ & $\bar{X}$ & SD & df & $F$ & $p$ \\
\hline \multirow{3}{*}{$\begin{array}{l}\text { First } \\
\text { factor }\end{array}$} & Unmarried & 256 & 9,183 & 5,894 & \multirow{3}{*}{2,772} & \multirow{3}{*}{3,964} & \multirow{3}{*}{0.002} \\
\hline & Married & 373 & 7,071 & 7,055 & & & \\
\hline & Divorced & 146 & 8,726 & 8,812 & & & \\
\hline \multirow{3}{*}{$\begin{array}{l}\text { Second } \\
\text { factor }\end{array}$} & Unmarried & 258 & 8,064 & 6,257 & \multirow{3}{*}{2,780} & \multirow{3}{*}{0,961} & \multirow{3}{*}{0.136} \\
\hline & Married & 376 & 7,210 & 5,941 & & & \\
\hline & Divorced & 149 & 9,735 & 6,360 & & & \\
\hline
\end{tabular}

Depending on personal marital status, unmarried respondents or divorced showed significantly higher values in the first factor compared with the married. In respect of attitudes related to economic dependence, there were established significant differences between respondents according to their marital status. 
Table 7. Differences by education.

\begin{tabular}{cccccccc}
\hline Score & Education & N & $\bar{X}$ & SD & df & F & p \\
\hline \multirow{2}{*}{$\begin{array}{c}\text { First } \\
\text { factor }\end{array}$} & Completed 8th Grade & 208 & 14,206 & 10,165 & & & \\
& Completed High-School & 316 & 11,125 & 8,412 & 2,777 & 3,214 & 0.003 \\
& Completed University & 256 & 7,116 & 6,033 & & & \\
\multirow{2}{*}{$\begin{array}{c}\text { Second } \\
\text { factor }\end{array}$} & Completed 8th Grade & 208 & 8,548 & 8,767 & & & \\
& Completed High-School & 317 & 9,106 & 6,891 & 2,781 & 0,475 & 0.536 \\
& Completed University & 258 & 9,927 & 7,212 & & & \\
\hline
\end{tabular}

Depending on the level of educational attainment, those with primary education showed more favorable attitudes towards economic dependence, compared with the respondents with secondary and higher education. In terms of attitudes towards independence, there was no significant difference between groups.

Table 8. Differences by income.

\begin{tabular}{cccccccc}
\hline Score & Income & N & $\bar{X}$ & SD & df & F & p \\
\hline \multirow{4}{*}{ First } & To 320 BGL & 218 & 14,375 & 11,065 & & & \\
factor & 321-600 BGL & 307 & 13,896 & 9,134 & & & \\
& 601-900 BGL & 125 & 10,310 & 8,086 & 4,778 & 3,208 & 0.003 \\
& 901-1200 BGL & 85 & 7,051 & 6,310 & & & \\
& Over 1200 BGL & 48 & 6,332 & 4,332 & & & \\
\hline \multirow{3}{*}{ fecond } & To 320 BGL & 216 & 5,801 & 4,896 & & & \\
& 321-600 BGL & 306 & 6,316 & 5,543 & & & \\
& 601-900 BGL & 126 & 10,132 & 9,017 & 4,774 & 2,592 & 0.005 \\
& $901-1200 \mathrm{BGL}$ & 83 & 13,903 & 8,898 & & & \\
& Over 1200 BGL & 48 & 12,764 & 9,541 & & & \\
\hline
\end{tabular}

Persons with a monthly income to $320 \mathrm{BGL}$ and persons with income from 321 to $600 \mathrm{BGL}$ demonstrate distinct attitudes towards economic dependence. There is a significant difference between these groups and the respondents with a higher monthly income. Respondents who have a monthly income of 601 to 900 BGL and those with income over 1200 BGL declare their favorable attitude towards economic independence. The difference between the estimates in their attitudes for the second factor compared to those who have a monthly income to $320 \mathrm{BGL}$ and persons with income of 321 to 600 BGL is statistically significant.

Table 9. Differences by age.

\begin{tabular}{cccccccc}
\hline Score & Age & N & $\bar{X}$ & SD & df & F & P \\
\hline \multirow{3}{*}{ First } & $18-35$ & 186 & 6,475 & 3,065 & & & \\
factor & $36-50$ & 230 & 7,182 & 5,874 & & & \\
& $51-65$ & 224 & 12,741 & 8,543 & & 2,718 & 0.005 \\
& Over 65 & 135 & 13,076 & 7,106 & & & \\
\hline
\end{tabular}




\begin{tabular}{cccccccc}
\hline Score & Age & N & $\bar{X}$ & SD & df & F & P \\
\hline \multirow{3}{*}{ Second } & $18-35$ & 186 & 14,640 & 12,682 & & & \\
factor & $36-50$ & 232 & 13,231 & 9,634 & & & \\
& $51-65$ & 224 & 8,562 & 7,420 & 3,774 & 2,820 & 0.004 \\
& Over 65 & 136 & 5,030 & 3,861 & & & \\
\hline
\end{tabular}

With increasing age increases the score on the first factor, but the score on the second factor decreases. This indicates that with increasing age, personality is oriented towards perceptions of economic dependence, while younger respondents' attitudes demonstrate economic independence.

Table 10. Differences by occupation.

\begin{tabular}{|c|c|c|c|c|c|c|c|}
\hline Score & Occupation & $\mathbf{N}$ & $\bar{X}$ & SD & df & $\mathbf{F}$ & $p$ \\
\hline \multirow{5}{*}{$\begin{array}{l}\text { First } \\
\text { factor }\end{array}$} & Students & 169 & 6,504 & 4,886 & \multirow{5}{*}{4,781} & \multirow{5}{*}{2,383} & \multirow{5}{*}{0.005} \\
\hline & Jobholders & 212 & 7,890 & 6,197 & & & \\
\hline & Pensioners & 124 & 11,076 & 9,064 & & & \\
\hline & Unemployed & 138 & 12,132 & 8,893 & & & \\
\hline & Businessmen & 143 & 5,412 & 4,510 & & & \\
\hline \multirow{5}{*}{$\begin{array}{l}\text { Second } \\
\text { factor }\end{array}$} & Students & 168 & 11,981 & 7,997 & \multirow{5}{*}{4,789} & \multirow{5}{*}{3,726} & \multirow{5}{*}{0.001} \\
\hline & Jobholders & 224 & 7,103 & 6,862 & & & \\
\hline & Pensioners & 126 & 5,816 & 4,650 & & & \\
\hline & Unemployed & 134 & 4,755 & 5,322 & & & \\
\hline & Businessmen & 142 & 12,014 & 8,071 & & & \\
\hline
\end{tabular}

Membership of a particular social group has a significant influence on the orientation towards attitudes of economic dependence or independence. Students and small business representatives demonstrate at the highest level attitudes toward economic independence where the difference with the other groups was statistically significant.

In the groups of employees, pensioners and the unemployed a high score is seen on the first factor, which is fundamentally different from that in the groups of students and businessmen. These results are expected because in all such studies pensioners and unemployed demonstrate positive attitudes towards economic dependence.

\section{Discussion}

As to the causes of dependence, the various theories differ, economic factors always dominate. Most theories concentrate on economic relations between a provider and a recipient. These theories stress the politico-economic interest while presented research is concentrated on the psychological aspects and internal structure of dependence which determines the socio-economic situation. According to Hirschman (1970), not a balanced growth should be aimed at, but rather existing imbalances - whose symptoms are profit and losses - must be maintained.

McClelland \& Burnham (1976) found that, regardless of our gender, culture, or age, we all have three motivating drivers, and one of these will be our dominant motivating driver. This dominant motivator is largely dependent on our culture and life experiences. Following the concept that the level of development is correlated with the achievement motivation, the present study tried to explain why this achievement motivation varies between societies and their classes and strata.

Children learn to act according to the established norms, and deviations are punished. If by external influences a new group gains power, the status of the old elite is challenged and weakened. 
The insecurity and frustration leads to the changed behavior which has consequences on the family structure. Children tend to become dissatisfied with the society and readily accept new values. In time, they become innovative personalities. If these persons become dominant groups in the society, this causes economic development Hagan et al. (1990).

All the theories discussed in the last years are only partial theories. They explain certain aspects of economic dependence - independence but do not fully explain the cause of this relation. The explanation is more adequate for certain socio-economic situations and specific conditions.

\section{Conclusions}

Results obtained from this study provide an opportunity to reveal the characteristics and content of attitudes towards economic dependence or independence. It was practically established, that the respondents tend to be assigned to the category of economically dependent or independent personalities. An attitude on a particular factor is strongly obverted at a higher positive score, while the lower is low affected.

Economic dependence is characterized by certain attitudes and representations typical of low-resource economic subjects (passiveness, low claims, uncertainty and insecurity in one's own abilities and opportunities, demand for external assistance and support, readiness for savings and material deprivation, behavioral strategies of economic inefficiencies, minimum level of material well-being, and the idea of "the best employer", etc.).

Economic independence reflects the attitudes and perceptions related to high-resource economic subjects (self-confidence and self ability to achieve economic success, high self-esteem and willingness to take strong economic risks, activeness, businesslike and entrepreneurship, perseverance to achieve a successful career, readiness for a new job, depending on the economic situation, security and the ability to control economic difficulties).

Definitely were proven certain individual characteristics of the respondents according to their attitude to economic dependence or independence. With increasing age the person is oriented towards attitudes of economic dependence. The respondents with primary education showed significantly more favorable attitudes towards economic dependence, compared with the respondents with secondary and higher education. Surveyed those who have a monthly income of 901BGL to 1200BGL, and those with the income over 1200BGL demonstrate a positive attitude towards economic independence. Membership in a particular socio-economic group has a significant influence on the orientation towards attitudes of economic dependence or independence. The presented scale can be used for research of attitudes towards economic dependence or independence and also for determination of individual characteristics of the respondents.

\section{References}

Ferrer-i-Carbonell, A. (2005). Income and well-being: an empirical analysis of the comparison income effect. Journal of Public Economics, 89, 997-1019.

Krastev, L. (2007). Naglasi I predstavi za peasant otnosheniia [Attitudes and representations of market relations]. Blagoevgrad, 132-145.

Barry B. (1976) Power: an Economic Analysis; Power and Political Theory: Some European Perspectives London: Wiley, 127-134.

Hagan, J., Gillis, A. R., Simpson, J. (1990). Clarifying and Extending Power - Control Theory. The American Journal of Sociology, 95 (4), 1024-1037.

Hirschman, A. (1970). Exit, voice and loyalty: Responses to decline in firms, organizations, and strategies. Cambridge, Massachusetts and Harvard University Press.

Lucas, R., Clark, A., Georgellis, Y., \& Diener, E. (2004). Unemployment alters the set-point for life satisfaction. Psychological Science, 15, 8-13.

McClelland, D. C., \& Burnham, D. H. (1976). Power is the great motivator. Harvard Business Review, 54 (2), 
100-110.

Molm, L., Takahashi, N., Peterson, G. (2000). Risk and trust in social exchange: An experimental test of a classical proposition. American Journal of Sociology, 105 (5).

Sweeney, P., \& McFarlin, D. (2004). Social comparisons and income satisfaction: A cross-national examination. Journal of Occupational and Organizational Psychology, 77, 149-54.

Yordanova, B. (2012). Parichni naglasi, finansova lokalizaciq na kontrola i koping strategii $v$ ikonomicheskoto povedenie na mladejite [Money attitudes, financial locus of control and coping strategies of economic behavior of youths.] Blagoevgrad, 15-17.

Advised by Stanislava Yordanova Stoyanova, South-West University "Neofit Rilski”, Bulgaria

Received: February 01, 2014

Accepted: March 25, 2014

Bilyana B. Yordanova Assistant Professor, South-West University, 66 Ivan Mihailov Street, Blagoevgrad, Bulgaria.

E-mail: b_iordanova@swu.bg

Lyudmil D. Krastev PhD., Professor, South-West University, 66 Ivan Mihailov Street, Blagoevgrad,

Bulgaria.

E-mail: iris@swu.bg 